\title{
The Analysis of Systems of Measurement for the Construction of Geometrical Models of the Product
}

\author{
Aleksandr Yurievich Brailov \\ Odessa State Academy of Civil Building and Architecture, Ukraine
}

\begin{abstract}
In the present work, the relevant components of the two basic system of measurement are defined through the analysis of existing systems of measurement for geometrical modeling. The major features of such systems related to the ways of formation of the two-dimensional complex drawing of a geometrical image on the basis of laws of projective connections are revealed. Interrelations of the elements of different systems of measurement with various projections of a geometrical image are defined. The relative location of projections of a geometrical image into the constructed two-dimensional complex drawings for various systems of measurement is discussed. The rationale behind a particular arrangement of views in the projective drawing of a product in the analyzed systems of measurement is explained.
\end{abstract}

Key words: Geometry, systems of measurement, image, projection, law, projective connections, drawing, interrelations, arrangement of views.

\section{Introduction}

In Australia, England, Holland, India, Japan, the United States of America (USA), and some other countries the American system of an arrangement of projections in engineering drawing is used. With respect to the front view, the top view is located above, the bottom view is located below, the left-side view - to the left, the right-side view - to the right of the front view, and the rear view - to the right of the product right-side view [1-5].

In Belarus, Germany, Kazakhstan, Kirgizstan, Poland, Russia, Ukraine and other countries the European system of an arrangement of projections in engineering drawing is used. Relative the front view, the top view is located below, the bottom view above, the left-side view — to the right, the right-side view - to the left of the front view, and the rear view — to the right of the product left-side view [1, 2, 6-7].

The Indian Standard Institution (ISI) and the British Standard Institution (BSI) recommend the use of First

Corresponding author: Aleksandr Yurievich Brailov, PhD, Professor, research fields: mechanical design, computer aided design, engineering computer graphics and computer design of tools. E-mail: brailov@gmail.com.
Angle Projection method (the European system) now in all the institutions too [10-11].

As a rule, at various universities of the world one any system of an arrangement of projections in the drawing is taught as applied in design and technological works of the given country [3-5, 12-17, 18-39].

It may happen that an engineer developing a production process comes across a part drawing where the views' arrangement is different than he leans. As a result, he or she may not adequately understand the drawing, and thus part design including tolerances and requirements. As a consequence, an inadequate manufacturing process can be developed and/or a good part can be rejected on its inspection.

Realizable ways of formation of projections and views in the drawing are connected in consciousness of an engineer with a particular system of measurement for construction of geometrical models of a product [2, 7, 40-51].

The American system of measurement for the construction of a geometrical model of a product differs from the European system of measurement. 
Thus, the essence of the problem (contradiction) consists in a necessity of adequate understanding understand the features of formation of projections in the drawing in used system of measurement by everyone involved in design and product manufacture adequately and lack of the systematized knowledge of features of various ways of formation of projections in different systems of measurement in the geometrical modeling.

Therefore, the purpose of this work is to reveal the features of various systems of the measurement used in the geometrical modeling, and to provide justifications for the arrangement of projections in the product drawing.

\section{Work Tasks}

1) To analyze the existing systems of measurement used in the geometrical modeling defining their relevant components.

2) To reveal the features of the known systems the measurements connected with the ways of formation of the two-dimensional complex drawing of a geometrical image.

3) To define interrelations of elements of the discussed systems of measurement with different projections of a geometrical image.

4) To define relative positioning of projections of a geometrical image in the two-dimensional complex drawing for various systems of measurement.

5) To carry out a logic substantiation of an arrangement of projections in the projective drawing of a product.

\section{The Main Part}

The first mutual component of the systems of measurement used for geometrical modeling is a set of three mutually perpendicular planes (Fig. 1).

In relation to the subject (to the student, the engineer, the researcher), one of these three planes is located horizontally $\left(\mathrm{H}-\Pi_{1}\right)$ whereas other two planes $\left(\mathrm{F}-\Pi_{2}, \mathrm{P}-\Pi_{3}\right)$ - vertically.

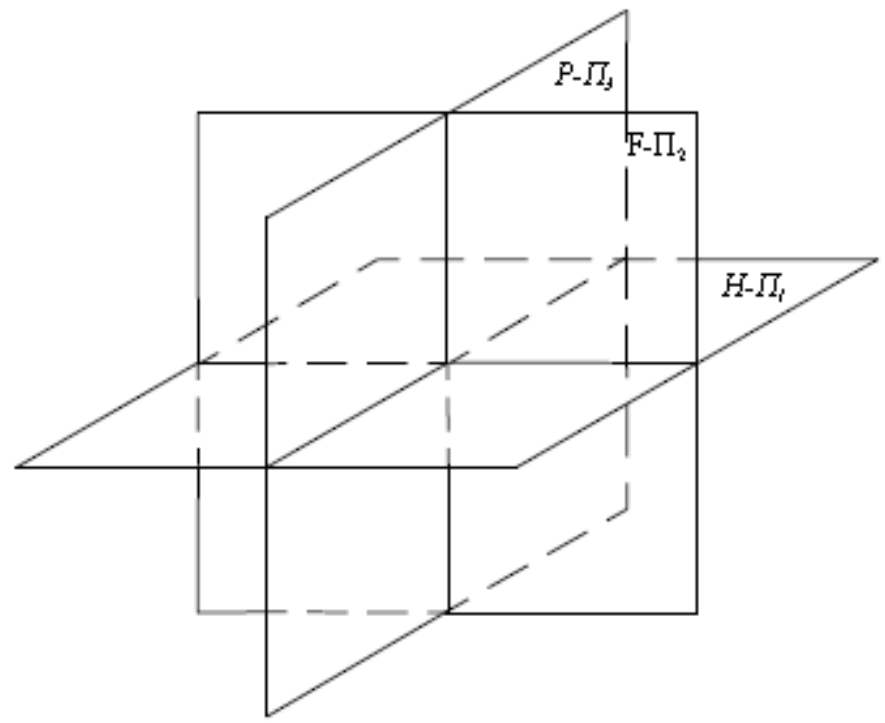

Fig. 1 Three mutually perpendicular planes of systems of measurement.

Horizontally focused plane $\mathrm{H}-\Pi_{1}$ is called as the horizontal plane. Vertically located plane $\mathrm{F}-\Pi_{2}$ is called as the frontal plane. Vertically focused plane $\mathrm{P}-\Pi_{3}$ is called as the profile plane.
For geometrical modeling, the method of orthogonal projections $[2,7,33]$ is used. In the method of orthogonal projections, horizontal plane $\mathrm{H}-\Pi_{1}$ is called as the horizontal plane of projections, frontal plane $\mathrm{F}-\Pi_{2}$ is called as the frontal plane of 
projections, and profile plane $\mathrm{P}-\Pi_{3}$ is called as the profile plane of projections.

The second mutual component of systems of measurement used for geometrical modeling is the right three-dimensional system of coordinates OXYZ, developed by Rene Descartes (1596-1650). The beginning of system of coordinates (a point O-Latin, origo) coincides with the point of intersection of all three planes.

Thus, the system of measurement for geometrical modeling consists of three mutually perpendicular planes $\mathrm{H}-\Pi_{1}, \mathrm{~F}-\Pi_{2}, \mathrm{P}-\Pi_{3}$ and connected with them right $[52,53]$ three-dimensional system of coordinates OXYZ.
The allocation of a way of orientation of the right three-dimensional system of coordinates OXYZ relative to the planes of projections $\mathrm{H}-\Pi_{1}, \mathrm{~F}-\Pi_{2}, \mathrm{P}-\Pi_{3}$ can be considered as the first feature of systems of measurement for geometrical modeling.

1) In Australia, England, Holland, Japan, the USA and a number of other countries, axes OZ and OX coincide with horizontal plane $\mathrm{H}-\Pi_{1}$, axes $\mathrm{OX}$ and $\mathrm{OY}$ are located in frontal plane $\mathrm{F}-\Pi_{2}$, and axes $\mathrm{OY}$ and $\mathrm{OZ}$ belong to profile plane $\mathrm{P}_{-} \Pi_{3}$ (Fig. 2). All axes of co-ordinates coincide with the lines of intersection of the discussed planes $[4,5]$.

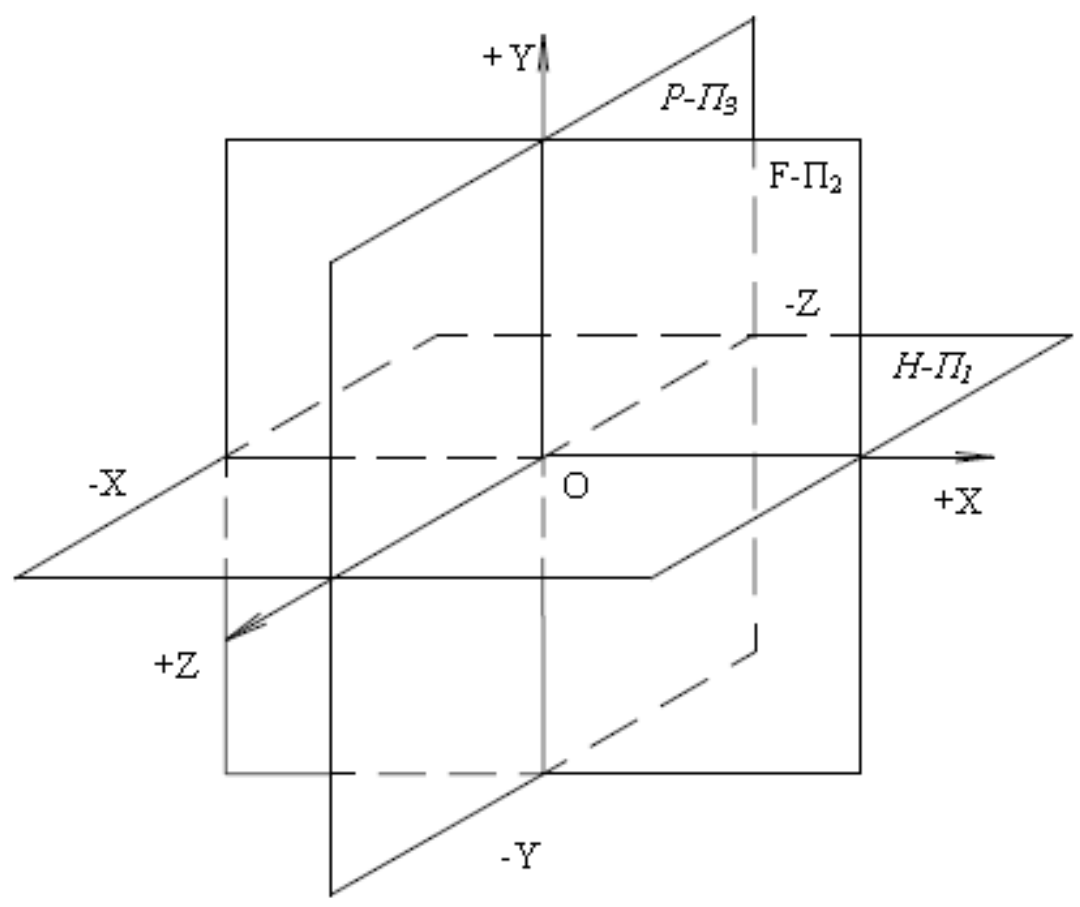

Fig. 2 Linking of the system of coordinates OXYZ with planes of projections $\mathrm{H}-\Pi_{1}, \mathrm{~F}-\Pi_{2}, \mathrm{P}-\Pi_{3}$ in the American system of measurement.

Because the positive direction of axis $\mathrm{OZ}$ relative to the origin $\mathrm{O}$ is directed to the subject (observer) for the right system of coordinates OXYZ, the positive coordinates of axis OX settle down to the right of the origin $\mathrm{O}$ and positive coordinates of axis $\mathrm{OY}$ are above the origin $\mathrm{O}$.

Thus, axis OY is directed upwards concerning the origin $\mathrm{O}$, axis $\mathrm{OX}$ is directed to the right concerning the origin $\mathrm{O}$, and axis $\mathrm{OZ}$ is directed from the origin $\mathrm{O}$ towards the observer [5].

Accordingly, the portion of axis OX with negative coordinates is to the left of profile plane $\mathrm{P}-\Pi_{3}$, the portion of axis OY with negative coordinates settles down below horizontal plane $\mathrm{H}-\Pi_{1}$, the portion of axis $\mathrm{OZ}$ with negative coordinates is behind frontal plane $\mathrm{F}-\Pi_{2}[5]$. 
The measurement system serves for placing and the description of geometrical images. Geometrical images are understood as abstract elements: a point, a line, a plane, a surface, a body [2, 6-9, 12-30].

The second feature of systems of measurement for geometrical modeling is the way of space partition into semi spaces, quadrants, and octants.

For the description of the location of an object in a particular measurement, space is partitioned by a plane into two semi spaces, by two orthogonal planes into four quadrants (quarters), by three mutually perpendicular planes into eight octants (parts).

2) In the American system of measurement, space is partitioned into four quadrants by horizontal plane $\mathrm{H}-\Pi_{1}$ and profile plane $\mathrm{P}-\Pi_{3}$ (Fig. 3 ).

The third feature of systems of measurement for geometrical modeling is the way of numbering of the allocated parts of space (semi spaces, quadrants, and octants).

3) In the American system of measurement, numerical values of coordinates $\mathrm{X}$ and $Y$ are positive for both axes $-1:+X,+Y$. In the second quadrant, numerical values of coordinate $Y$ are positive, and coordinates $X$ are negative $-2:-X,+Y$. In the third quadrant, numerical values of coordinates $X$ and $\mathrm{Y}$ are negative for both axes -3 : $-\mathrm{X},-\mathrm{Y}$. In the fourth quadrant, numerical values of coordinate $Y$ are negative, and coordinates $X$ are positive $-4:+X,-Y$ [5].

Quadrant number increase at consecutive viewing the quadrants from the positive direction $+Z$ axes $O Z$ counter-clockwise (Fig. 3). Numbers 1, 2, 3, 4 quadrants are specified around the image.

The one eighth part of space, in which all numerical values of coordinates $\mathrm{X}, \mathrm{Y}, \mathrm{Z}$ for three axes $\mathrm{OX}, \mathrm{OY}$, $\mathrm{OZ}$ are positive $+\mathrm{X},+\mathrm{Y},+\mathrm{Z}$ is chosen as the first octant.

Numbers of the first four octants correspond to four numbers quadrants (quarters). The fifth, the sixth, the seventh and the eighth octants are bred behind the frontal plane of projections $\mathrm{F}-\Pi_{2}$ from the positive direction $+\mathrm{Z}$ axis $\mathrm{OZ}$ accordingly in the first, in the second, in the third and the fourth quadrant (Fig. 3).

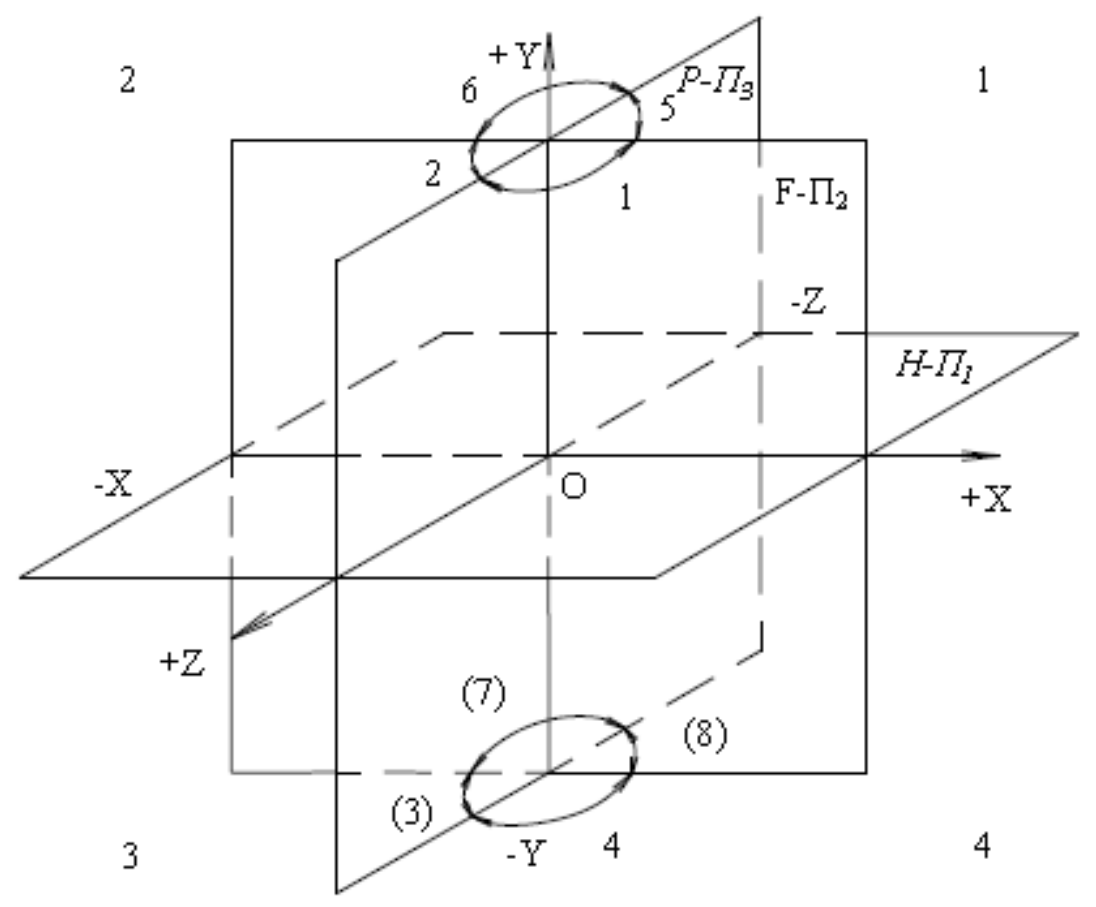

Fig. 3 Quadrants and octants numbering in the American system of measurement. 
The revealed features of the American system of measurement differ from similar characteristics of the European system of measurement although there are some similarities.

1) In the European system of measurement, the right $[52,53]$ the three-dimensional system of coordinates OXYZ is positioned differently relative to the planes of projections $\mathrm{H}-\Pi_{1}, \mathrm{~F}-\Pi_{2}$, Р-Пз (Fig. 1) as shown in Fig. 4.

Axes $\mathrm{OZ}$ and $\mathrm{OX}$ coincide with frontal plane $\mathrm{F}-\Pi_{2}$, axes OX and OY settle down in horizontal plane $\mathrm{H}-\Pi_{1}$, and axes $\mathrm{OY}$ and $\mathrm{OZ}$ also belong to profile plane Р-Пз (Fig. 4). All the axes of coordinates are coincident with the intersection lines of the projection planes [7]. system of coordinates OXYZ, the positive coordinates of axis $\mathrm{OX}$ are to the left of the origin $\mathrm{O}$ and positive coordinates of axis OY settle down before frontal plane F-П2 closer to the observer to the origin O (Fig. 4).

Thus, axis OY is directed from the origin $\mathrm{O}$ coordinates towards the observer, axis $\mathrm{OX}$ is directed to the left of the origin $\mathrm{O}$, axis $\mathrm{OZ}$ is directed upwards relative to the origin $\mathrm{O}$.

Accordingly, the portion of axis OX with negative coordinates is to the right of profile plane $\mathrm{P}-\Pi_{3}$, the portion of axis OY with negative coordinates settles down behind frontal plane $\mathrm{F}-\Pi_{2}$, the portion of axis $\mathrm{OZ}$ with negative coordinates is below horizontal plane Н-П1 [7].

Because the positive direction of axis $\mathrm{OZ}$ with respect to the origin $\mathrm{O}$ is directed upwards for the right

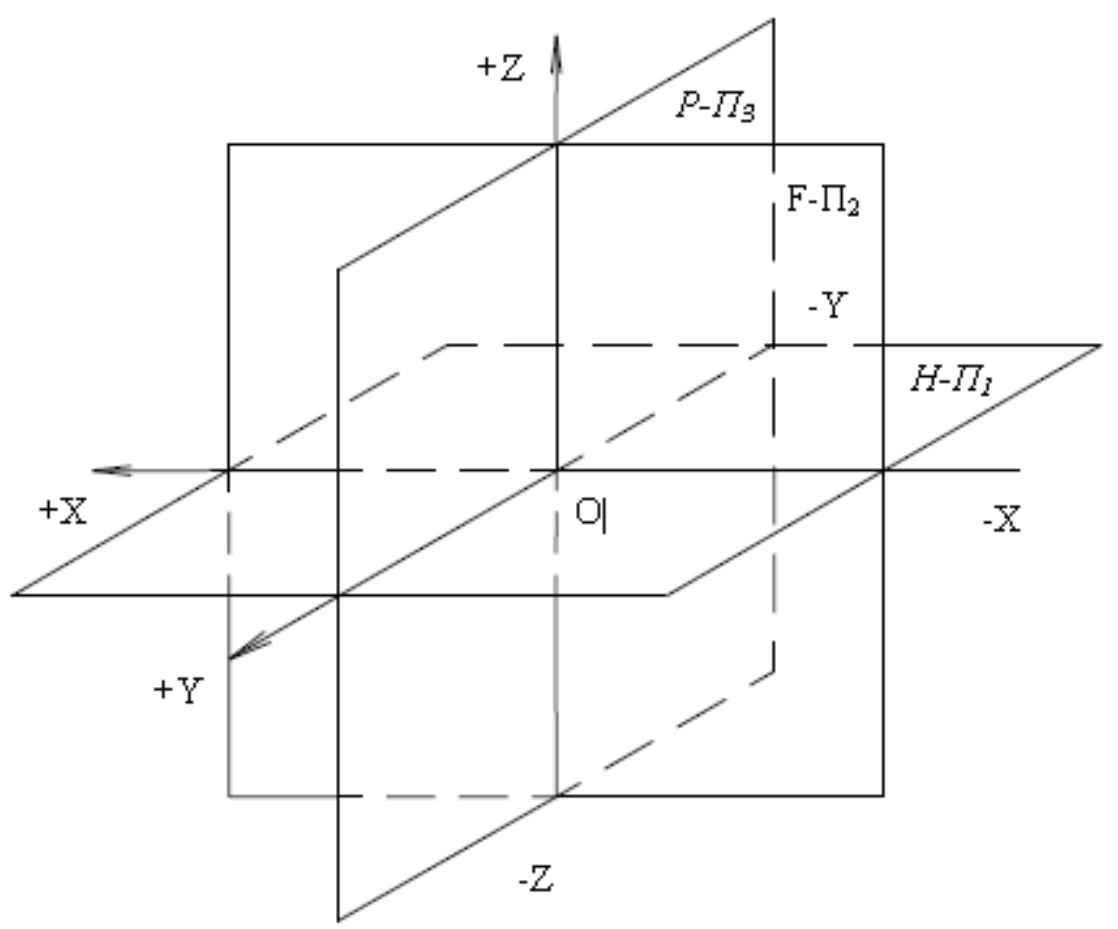

Fig. 4 Linking of system of coordinates OXYZ with planes of projections H-П1, F-П2, Р-П3 in the European system of measurement.

2) In the European system of measurement, space is partitioned into four quadrants by horizontal plane $\mathrm{H}-\Pi_{1}$ and frontal plane $\mathrm{F}-\Pi_{2}$ (Fig. 5).

3) The way of numbering quadrants in the European system of measurement differs from the American system of measurement. In the first, quadrant numerical values of coordinates $Z$ and $Y$ are positive for both axes $-1:+Z,+Y$. In the second quadrant, numerical values of coordinate $Z$ are positive, and coordinates $Y$ are 
negative -2 : $+\mathrm{Z},-\mathrm{Y}$. In the third quadrant, numerical values of coordinates $Z$ and $Y$ are negative for both axes -3 : $-Z,-Y$. In the fourth quadrant, numerical values of coordinate $\mathrm{Z}$ are negative, and coordinates $\mathrm{Y}$ are positive - 4: $-\mathrm{Z},+\mathrm{Y}$ [4]. The quadrant number increases at consecutive viewing quadrants from the positive direction $+X$ axes $O X$ counter-clockwise (Fig. 5).

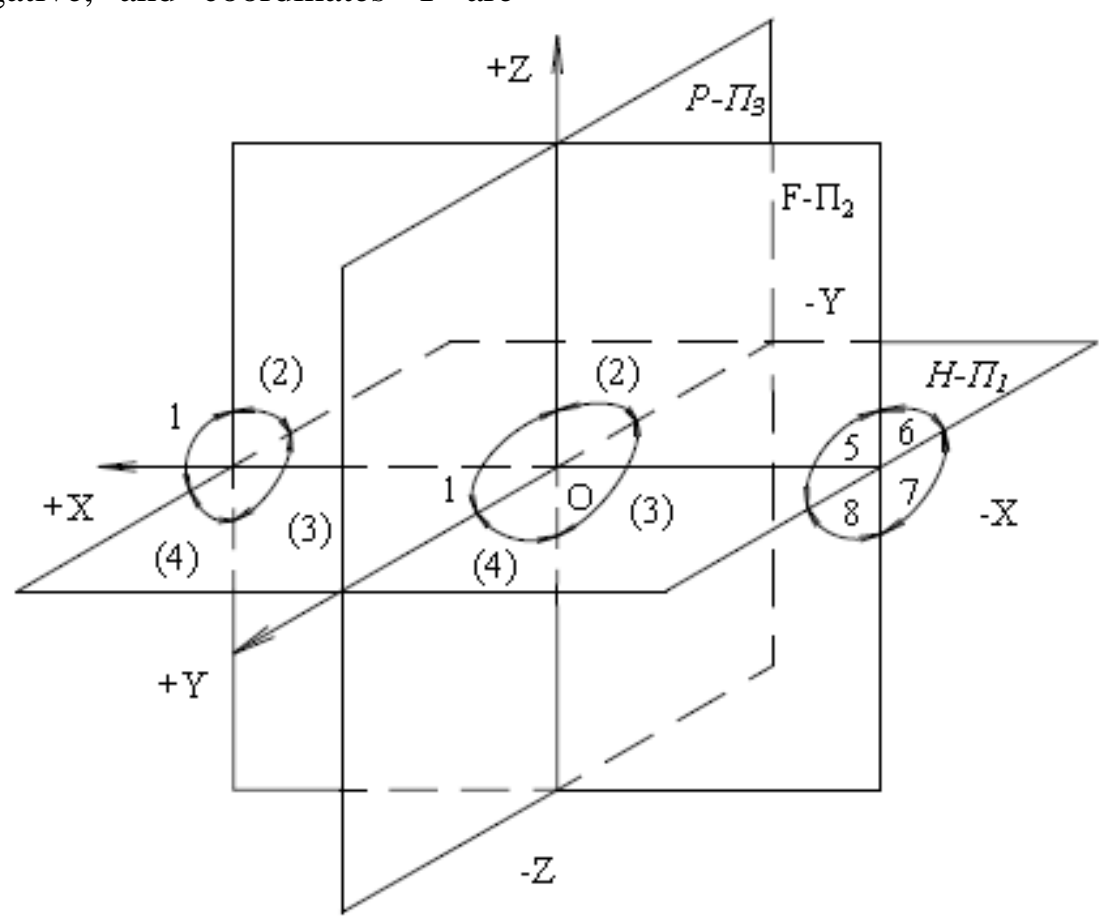

Fig. 5 Quadrants and octants numbering in the European system of measurement.

In the European system of measurement, the same as in the American system of measurement, the first octant is chosen as one eighth part of space, in which all the numerical values of coordinates $\mathrm{X}, \mathrm{Y}, \mathrm{Z}$ for three axes $\mathrm{OX}, \mathrm{OY}, \mathrm{OZ}$ are positive $+\mathrm{X},+\mathrm{Y},+\mathrm{Z}$ is chosen.

The difference for the first octant in the European system is that horizontal plane $\mathrm{H}-\Pi_{1}$ is located between axes OX and OY whereas in the American system frontal plane F-П2 settles down, and frontal plane F-П2 (Fig. 5) is located between axes OX and OZ, instead of horizontal plane $\mathrm{H}-\Pi_{1}$ (Fig. 2, 3) in the American system.

Numbering of the first, the second, the third and the fourth octants, located to the left of profile plane Р-Пз, coincides with numbering of the first, the second, the third and the fourth quadrants the European system (Fig. 5).
The fifth, the sixth, the seventh and the eighth octants in the European system settles down to the right of profile plane Р-Пз accordingly in the first, the second, the third and the fourth quadrants (Fig. 5).

Let's consider construction of model of a geometrical image in the American system of measurement.

The third octant in the third quadrant is used in the American system of measurement for construction of model of a geometrical image (Fig. 3).

Therefore, segment $\mathrm{AB}$ of a straight line settles down in the third octant (Fig. 6).

The method of rectangular (orthogonal) projection is applied to construct the projections of segment $\mathrm{AB}$ [45].

The results of projection of segment $\mathrm{AB}$ into three mutually perpendicular planes $\mathrm{F}-\Pi_{2}, \mathrm{H}-\Pi_{1}, \mathrm{P}-\Pi_{3}$ are frontal projection $\mathrm{AfBf}$, horizontal projection $\mathrm{AhBh}$ and 
profile projection $\mathrm{Ap}_{\mathrm{p}} \mathrm{B}_{\mathrm{p}}$ [46]. The constructed three-dimensional geometrical model of segment $\mathrm{AB}$ is shown at the left site in Fig. 6.

For the development of a two-dimensional complex drawing from a three-dimensional geometrical model, segment $\mathrm{AB}$ and projecting rays $\mathrm{AAf}, \mathrm{AAh}, \mathrm{AAp}, \mathrm{BBf}$, $\mathrm{BBh}, \mathrm{BB}_{\mathrm{p}}$ are mentally removed. Horizontal plane $\mathrm{H}-\Pi_{1}$ with projection $\mathrm{AhBh}$ of the segment are rotated around the axis OX clockwise from the positive direction $+\mathrm{X}$ till its full coincidence with frontal plane F-П2. Profile plane $\mathrm{P}-\Pi_{3}$ with projection $\mathrm{Ap}_{\mathrm{p}} \mathrm{B}_{\mathrm{p}}$ of the segment are rotated around the axis OY counter-clockwise from the positive direction $+Y$ till its full coincidence with frontal plane F-П2. The constructed two-dimensional geometrical model of segment $\mathrm{AB}$ is shown on the right site in Fig. 6.

For the American system of measurement in the two-dimensional complex drawing of a geometrical image, the horizontal projection is located above the frontal projection, and the profile projection is located to the right of the frontal projection (Fig. 6).

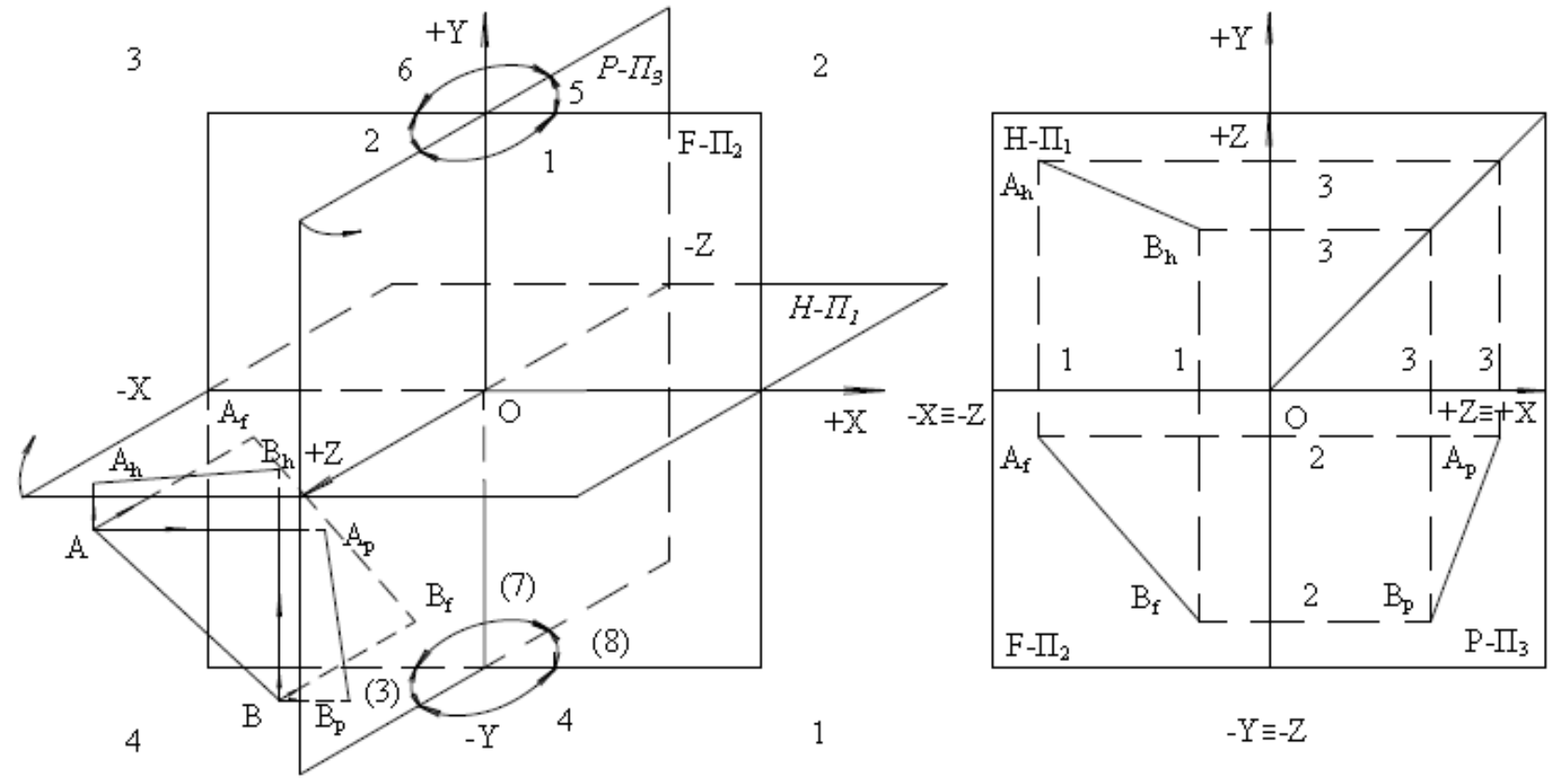

Fig. 6 Geometrical models of segment $\mathrm{AB}$ of a straight line in the American system of measurement.

Constructed frontal projection $\mathrm{AfBf}$, horizontal projection $\mathrm{AhBh}_{h}$ and profile projection $\mathrm{A}_{\mathrm{p}} \mathrm{B}_{\mathrm{p}}$ of segment AB satisfy the laws of projective connections 1-1, 2-2, 3-3 [7, 49].

Elements of the American system of measurement are unambiguously connected with the projections of a geometrical image.

a) Negative coinciding portions $-\mathrm{X} \equiv-\mathrm{Z}$, $-\mathrm{Y} \equiv-\mathrm{Z}$ of axes $\mathrm{X}$ and $\mathrm{Y}$ and axes of ordinates, applicates OY, OZ limit frontal plane $\mathrm{F}-\Pi_{2}$ and the frontal projection of a geometrical image. b) Coinciding negative portions $-\mathrm{X} \equiv-\mathrm{Z}$ of axes $\mathrm{OX}, \mathrm{OZ}$ and coinciding positive portions $+\mathrm{Y}=+\mathrm{Z}$ of axes $\mathrm{OY}, \mathrm{OZ}$ limit horizontal plane $\mathrm{H}-\Pi_{1}$ and the horizontal projection of a geometrical image.

c) Coinciding negative portions $-\mathrm{Y} \equiv-\mathrm{Z}$ of axes $\mathrm{OY}, \mathrm{OZ}$ and coinciding positive portions $+\mathrm{X}=+\mathrm{Z}$ of axes $\mathrm{OX}, \mathrm{OZ}$ limit profile plane $\mathrm{P}-\Pi_{3}$ and the profile projection of a geometrical image.

For the realized way of construction of the complex drawing (Fig. 6) in the American system of 
measurement, the horizontal projection is the bottom view, and the profile projection is the left-side view.

Thus, if planes of projections are considered to be opaque in the projective drawing of a product then the bottom view settles down from above the front view and the left-side view settles down to the right of the front view. Conversely, in the countries using the American system of measurement, the bottom view settles down from below from the front view, and the left-side view settles down to the left of the front view. Conditions needed for realization of such accepted

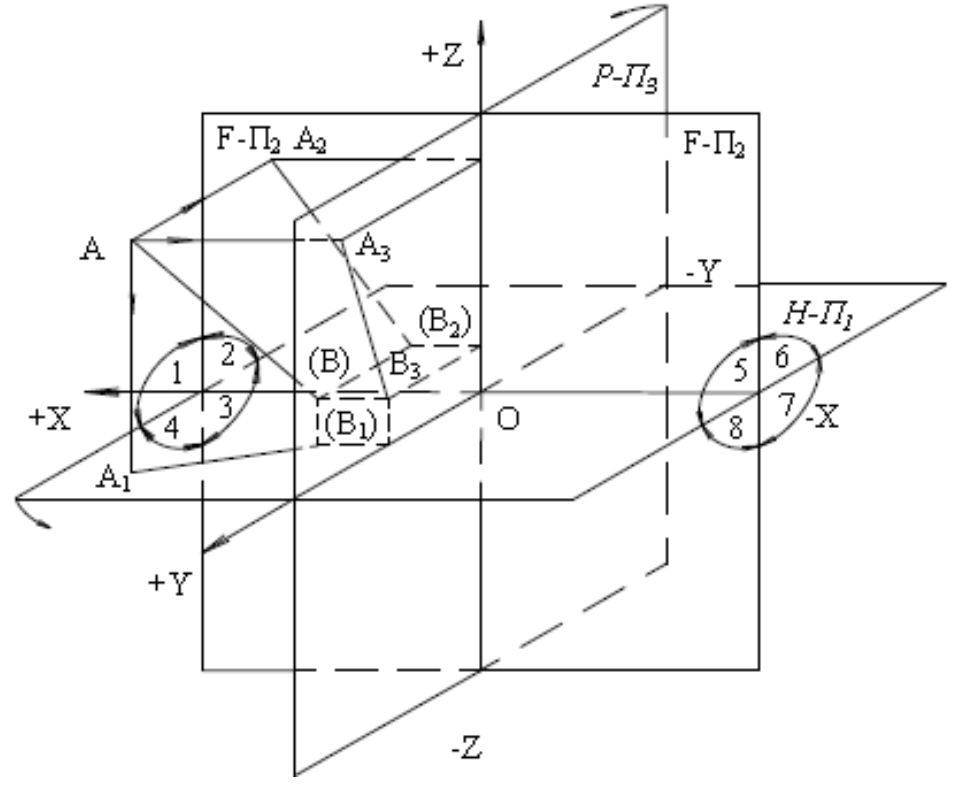

arrangement of views in the projective drawing of a product will be considered in the separate publication.

Let's consider the construction of model of a geometrical image in the European system of measurement.

In the European system of measurement, the first octant in the first quadrant is used for construction of model of a geometrical image as shown in Fig. 5.

That is why segment $\mathrm{AB}$ of a straight line settles down in the first octant (Fig. 7).

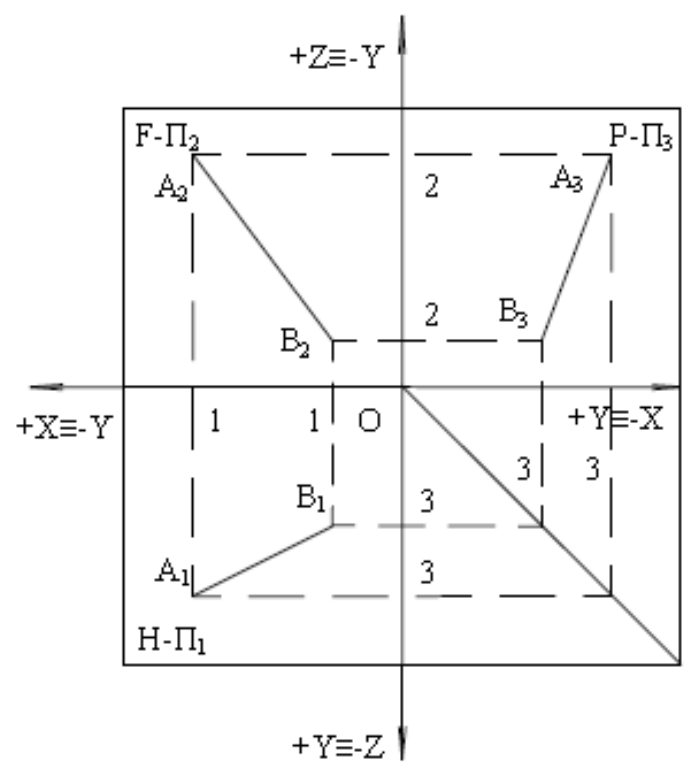

Fig. 7 Geometrical models of segment $\mathrm{AB}$ of a straight line in the European system of measurement.

The method of orthogonal projecting is also applied to develop projections of segment $\mathrm{AB}$ [33].

The results of projections of segment $\mathrm{AB}$ into three mutually perpendicular planes $\mathrm{F}-\Pi_{2}, \mathrm{H}-\Pi_{1}$, and $\mathrm{P}-\Pi_{3}$ are the frontal projection $\mathrm{A}_{2} \mathrm{~B}_{2}$, horizontal projection $\mathrm{A}_{1} \mathrm{~B}_{1}$ and profile projection $\mathrm{A}_{3} \mathrm{~B}_{3}$ [7]. The constructed three-dimensional geometrical model of segment $\mathrm{AB}$ is shown to the left in Fig. 7.

For construction of the two-dimensional complex drawing from three-dimensional geometrical model, segment $\mathrm{AB}$ and projecting rays $\mathrm{AA} 2, \mathrm{AA}_{1}, \mathrm{AA}_{3}, \mathrm{BB}_{2}$, $\mathrm{BB} 1, \mathrm{BB} 3$ are mentally removed.

Horizontal plane $\mathrm{H}-\Pi_{1}$ with projection $\mathrm{A}_{1} \mathrm{~B}_{1}$ of segment $A B$ is rotated about the axis of abscissas $O X$ clockwise from a positive direction $+\mathrm{X}$ till its full coincidence with frontal plane F-П2. Profile plane Р-Пз with projection $\mathrm{A}_{3} \mathrm{~B} 3$ of segment $\mathrm{AB}$ is rotated about the axis of applicate $\mathrm{OZ}$ counter-clockwise from a positive direction $+Z$ till its full coincidence with frontal plane $\mathrm{F}-\Pi_{2}$. The constructed two-dimensional geometrical model of segment $\mathrm{AB}$ is shown to the right in Fig. 7.

A two-dimensional geometrical model is called as the complex drawing of a geometrical image [7, 8, 22-25].

For the European system of measurement in the two-dimensional complex drawing of a geometrical image, the horizontal projection is located below the frontal projection, and the profile projection is located to the right of the frontal projection (Fig. 7). 
Constructed frontal projection $\mathrm{A}_{2} \mathrm{~B}_{2}$, horizontal projection $\mathrm{A}_{1} \mathrm{~B}_{1}$ and profile projection $\mathrm{A}_{3} \mathrm{~B} 3$ of segment $\mathrm{AB}$ also satisfy the laws of projective connections 1-1, 2-2, 3-3 [7, 49].

Elements of the European system of measurement also correlated with different projections of a geometrical image as follows:

1) Coinciding $(+X \equiv-Y)$ the positive portion of the axis of abscissas $\mathrm{OX}$ and the negative portion of the axis of ordinates $\mathrm{OY}$, and also coinciding $(+\mathrm{Z} \equiv-\mathrm{Y})$ the positive portion of the axis $\mathrm{OZ}$ and the negative portion of the axis of ordinates OY limit frontal plane $\mathrm{F}-\Pi_{2}$ and the frontal projection of a geometrical image.

2) Coinciding $(+\mathrm{X} \equiv-\mathrm{Y})$ the positive portion of the axis of abscissas $\mathrm{OX}$ and the negative portion of the axis of ordinates OY, and also coinciding $(+\mathrm{Y} \equiv-\mathrm{Z})$ the positive portion of the axis of ordinates $\mathrm{OY}$ and the negative portion of the axis OZ limit horizontal plane $\mathrm{H}-\Pi_{1}$ and the horizontal projection of a geometrical image.

3) Coinciding $(+\mathrm{Z} \equiv-\mathrm{Y})$ the positive portion of the applicate axis $\mathrm{OZ}$ and the negative portion of the axis of ordinates OY, and also coinciding $(+\mathrm{Y} \equiv-\mathrm{X})$ the positive portion of the axis of ordinates $\mathrm{OY}$ and the negative portion of the axis of abscissas OX limit profile plane $\mathrm{P}-\Pi_{3}$ and the profile projection of a geometrical image.

For the realized way of construction of the complex drawing (Fig. 7) in the European system of measurement, the horizontal projection is the top view, and the profile projection is the left-side view.

Hence, if planes of projections to consider opaque on the projective drawing of a product, the top view is located below the front view and the left-side view is located to the right of the front view. Such an arrangement of views corresponds to the accepted arrangement of views in the projective drawing of a product in the countries where the European system of measurement is used.

\section{Conclusions}

1) Three mutually perpendicular planes $\mathrm{H}-\Pi 1$, F-П2, Р-ПЗ are considered as the components of system of measurement for geometrical modeling. The right three-dimensional system of coordinates OXYZ is allocated to determine the coordinates in these planes.

2) The way of orientation of the right three-dimensional system of coordinates OXYZ with respect to the set planes of projections $\mathrm{H}-\Pi 1$, F-П2, Р-ПЗ is the first feature of systems of measurement. In the American system of measurement, the axes $\mathrm{OZ}$ and $\mathrm{OX}$ coincide with horizontal plane $\mathrm{H}-\Pi 1$, the axes OX and OY settle down in frontal plane F-П2, and axes OY and $\mathrm{OZ}$ belong to profile plane Р-ПЗ (Fig. 2). In the European system of measurement, the axis $\mathrm{OZ}$ and $\mathrm{OX}$ coincide with frontal plane $\mathrm{F}-\Pi 2$, axes OX and OY settle down in horizontal plane $\mathrm{H}-\Pi 1$, and axes $\mathrm{OY}$ and $\mathrm{OZ}$ also belong to profile plane Р-П3 (Fig. 4).

3) The second feature of systems of measurement for geometrical modeling is the way of conditional division of space into parts: semi spaces, quadrants, and octants. In the American system of measurement, the space is divided into four quadrants by horizontal plane Н-П1 and profile plane Р-ПЗ as shown in Fig. 3. In the European system of measurement, the space is divided into four quadrants by horizontal plane Н-П1 and frontal plane F-П2 (Fig. 5).

4) The third feature of systems of measurement for geometrical modeling is the order of numbering of the allocated parts of space (semi spaces, quadrants, and octants). In the American system of measurement, this order shown in Fig. 3 differs from that used in the European system of measurement (Fig. 5). 
5) Interrelations of elements American (Fig. 6) and European (Fig. 7) systems of measurement with different projections of a geometrical image in the two-dimensional complex drawing are not the same. The differences result in the various arrangements of views in the projective drawing of a product.
A way of elimination of discrepancy of projections of an image and views of a product for the American system we will consider in a separate research [54].

An attempt to reach conformity of projections of an image (Fig. 6) and proper visualization of product views under the American standard (ISO A of ISO 5456) by simple turn of planes of projections in other direction leads to loss of clearness of the drawing of a geometrical image (Fig. 8).

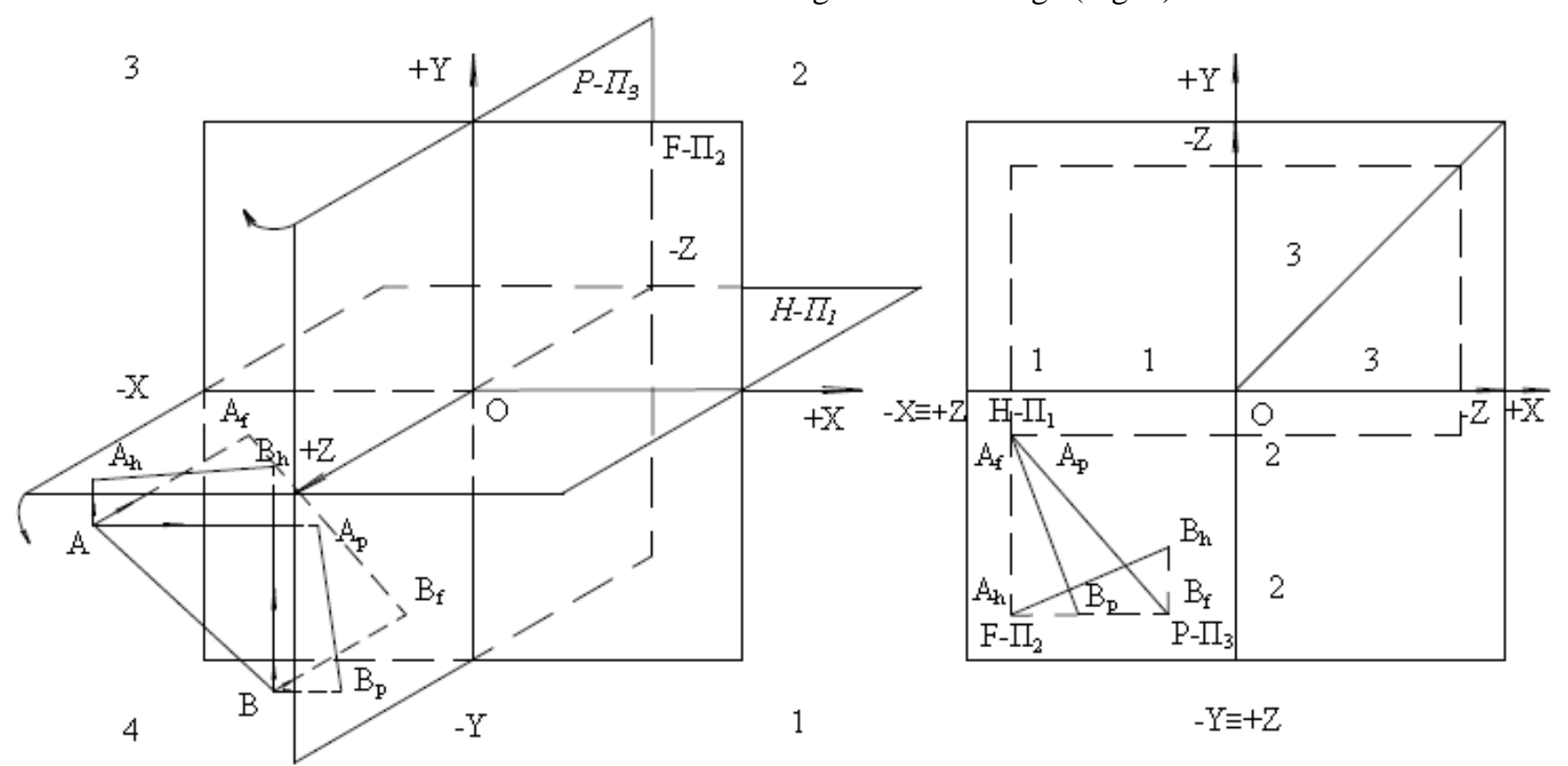

Fig. 8 The rotation of the plane $H$ into the vertical position performed in the other direction (down). The same holds for the profile plane $P$ (Left).

\section{Acknowledgments}

I am sincerely grateful to Professor Astakhov Victor Pavlovich for the help with editing of the English text of the manuscript.

I am sincerely grateful to Professor Stachel Hellmuth for the offered kind help in preparation of materials.

I am sincerely grateful to close friends and colleagues, to all people in my life I love and care about!

\section{References}

[1] Automation of the designing and preparation production. T-FLEX Parametric CAD, Moscow, Top Systems Publ., 2002, p. 41 (in Russian).
[2] Brailov A. Yu (2007). Computer Engineering Graphics in the Environment of T-FLEX: Transformations of Two-Dimensional and Three-Dimensional Models of Products. Kiev, Caravella Publ., p. 176 (in Russian).

[3] Cervantes-Sanchez, J. J. and Zsombor-Murray, P. (2014). "Kinematics of a Mobile Overconstrained RRRCR Loop." Proceedings of the 16th International Conference on Geometry and Graphics, Innsbruck, AUSTRIA, pp. 726-731.

[4] Honma, I. (2012). “A Trial with Teaching Materials on Descriptive Geometry by Using CAD for Students with Hearing Impairments." Proceedings of the Fifteenth International Conference on Geometry and Graphics, Montreal, CANADA, ISGG, pp. 296-301.

[5] Ryan, D. L. (1992). CAD/CAE Descriptive Geometry. Boca Raton: CRC Press, p. 209.

[6] Brailov A. Yu (2013). "The General Algorithm of the Solution of Typical Geometrical Problems: Applied 
Geometry and the Engineering Graphics.” Kiev, KNUBA Publ., Issue 91, pp. 32-45. (in Russian).

[7] Brailov A. Yu (2013). “Engineering Geometry.” Kiev: Caravella Publ.: 456. (in Russian).

[8] Bubennikov, A. V. and Gromov, M. Ya (1973). “Descriptive Geometry.” Vishaya shkola Publ.: 416 (in Russian).

[9] Vanin, V. V., Bliok, A. V., and Gnitecka, G. O. (2003). Appearance of Design Documentation. Kiev, Caravella Publ., p. 160 (in Ukrainian).

[10] BRITISH STANDARD BS 8888:2011 Technical Product Documentation and Specification. London: BSI Standard Publication, 2011. - 94 pp. (ISBN 978-0-580-72757-3).

[11] INDIAN STANDARD IS 15021 (Part 2): 2001, ISO 5456-2:1996 Technical Drawings - Projection Methods, Part 2 Orthographic Representations. New Delhi: Bureau of Indian standards, 2001, p. 12 p.

[12] Glazunov, E. A. and Chetverukhin, N. F. (1953). Axonometry. Moscow, p. 291 (in Russian).

[13] Ivanov, G. S. (1987). "Design of Engineering Surfaces.” Mashinostroenie Publ.: 192 (in Russian).

[14] Ivanov, G. S. (1995). "Descriptive Geometry." Mashinostroenie Publ.: 223 (in Russian).

[15] Ivanov, G. S. (1998). "Theoretical foundations of Descriptive Geometry.” Mashinostroenie Publ.: 158 (in Russian).

[16] Ivanov, Yu N., Podkoritov, A. N., Strigo and Yu S. (1962). "Descriptive Geometry." Oмsк, Oмsкауа Pravda Publ.: 232 (in Russian).

[17] Mihajlenko, V. E., Kovalyev, S. N., Sedleckaya, N. I. and et al. (1989). "Engineering Geometry with Element of the Theories Of Parameterization.” Kiev, UMK VO Publ.: 83 (in Russian).

[18] Kotov, I. I., Polozov, V. S. and Shirokova, L. V. (1977). “Algorithms of Computer Graphics.” Mashinostroenie Publ.: 231 (in Russian).

[19] Kolotov, S. M., Dolski, E. E., Mihajlenko V. E. and et al. (1961). "Course of Descriptive Geometry." Gosstrojizdat USSR Publ.: 314 (in Russian).

[20] Tevlin, A. M., Ivanov, G. S., Nartova, L. G. and et al. (1983). Course of Descriptive Geometry on the Ground of Computer. Edited by A. M. Tevlin. Moscow: Vishaya shkola Publ., p. 175 (in Russian).

[21] Levicki, V. S. (1988). Machine-Building Drawing. Moscow: Vishaya shkola Publ., p. 351 (in Russian).

[22] Mihajlenko, V. E., Vanin, V. V. and Kovalyev, S. N. (2013). Engineering and Computer Graphics: Handbook. Edited by V. E. Mihajlenko. Kiev, Karavella Publ., p. 328 (in Russian).

[23] Mihajlenko, V. E., Najdish, V. M., Podkorytov, A. N., and Skidan I. A. (2001). Engineering and Computer
Graphics. Kiyv, Vishcha shkola Publ., p. 350 (in Russian).

[24] Mihajlenko, V. E., Najdish, V. M., Podkorytov, A. N., and Skidan I. A. (2002). Problems in the Engineering And Computer Graphics. Kiyv, Vishcha Shkola Publ., p. 159 (in Russian).

[25] Podkorytov, A. N., Galzman, E. G. and Perevalov, V. F. (1993). Lectures on Engineering Graphics (with Structurally Logic Schemes and Algorithms of Graphic Constructions in Solving Typical Problems) for Students of Non-Mechanical Specialties. Odessa, OSPU Publ., p. 83 (in Russian).

[26] Romanicheva, E. T., Sokolova, T. Yu. and Shandurina, G. F. (2001). Engineering and Computer Graphics. Moscow, DMK Press Publ., p. 592 (in Russian).

[27] Russian Complex of the Programs T-FLEX CAD/CAM/CAE/PDM. Moscow: Top Systems Publ., 2005, p. 52 (in Russian).

[28] Rizhov, N. N. (1983). Main Positional Problems. Moscow: MADI Publ., p. 38 (in Russian).

[29] Rizhov, N. N. (1988). Parametric Geometry. Moscow: MADI Publ., p. 63 (in Russian).

[30] Frolov, S. A. (1978). Descriptive Geometry. Moscow, Mashinostroenie Publ., p. 240 (in Russian).

[31] Cardone, V., Iannizzaro, V., Barba, S. and Messina, B. (2012). “Computer Aided Descriptive Geometry.” In: Proceedings of the Fifteenth International Conference on Geometry and Graphics. Montreal, Canada, ISGG, pp. 100-109.

[32] Cucakovic, A. A., Teofilovic, N. K. and Jovic, B. S. (2014). "Descriptive Geometry Education by Using Multimedia Tools.” In: Proceedings of the 16th International Conference on Geometry and Graphics. Innsbruck, Austria, pp. 262-265.

[33] Monge, G. (1850). Application de l'Analyse à la Géométrie. Bachalier, Paris.

[34] Schmitt, F. (2004). "Descriptive Geometry and 3D-CAD”. In: Proceedings of the Eleventh International Conference on Geometry and Graphics. Guangzhow, China, ISGG, pp. 257-262.

[35] Stachel, H. (2006). "Descriptive Geometry Meets Computer Vision - The Geometry of Multiple Images.” In: Proceedings of the Twelfth International Conference on Geometry and Graphics. Salvador, Brazil, ISGG, Paper \#T30.

[36] Suzuki, K. (2014). "Traditional Descriptive Geometry Education in 3D-CAD/CG Era.” Journal for Geometry and Graphics 18 (2): 249-258.

[37] Volkov V. Ya, Yurkov V. Yu, Panchuk K. L., Ilyasova, O., Kaygorodtseva, N., and Yakovenko, K. (2012). “The Innovative Paradigm of Teaching in Descriptive Geometry.” In: Proceedings of the Fifteenth International 
Conference on Geometry and Graphics. Montreal, Canada, ISGG, pp. 778-787.

[38] Weiss, G. (2012). "Is Advanced Elementary Geometry on the Way to regain Scientific Terrain?” In: Proceedings of the Fifteenth International Conference on Geometry and Graphics. Montreal, Canada, ISGG, pp. 793-804.

[39] Wu, H. and Suzuki, K. (2012). "Development of Spatial Ability of Students During Elementary-, Junior High-, and Senior High-Schools." In: Proceedings of the Fifteenth International Conference on Geometry and Graphics. Montreal, Canada, ISGG, pp. 815-823.

[40] Brailov A. Yu (1998). "The Exclusion Method of Interference in Conjugated Helicoids.” In: Proceedings of the Eighth International Conference on Engineering Design Graphics and Descriptive Geometry. Austin, Texas, USA, ISGG, Vol. 2, pp. 443-445.

[41] Brailov A. Yu (1999). "Physical Constraints in the Control of Chip Breakability." ASME Journal of Manufacturing Science and Engineering 10: 389-396.

[42] Brailov A. Yu., and Tigaryev V. M. (2000). "Graphic Method of Determination of Ranges of a Modification of Parameters of Complicated Movements.” In: Proceedings of the Ninth International Conference on Engineering Design Graphics and Descriptive Geometry. Johannesburg, South Africa, ISGG, Vol. 2, pp. 412-416.

[43] Brailov A. Yu (2002). "Interference in Design." In: Proceedings of the Tenth International Conference on Geometry and Graphics. Kiev, Ukraine, ISGG, Vol. 1, pp. 84-88.

[44] Brailov A. Yu (2004). "Designing Using T-FLEX CAD.” In: Proceedings of the Eleventh International Conference on Geometry and Graphics. Guangzhou, China, ISGG, pp. 397-402.

[45] Brailov A. Yu (2006). "Development of a Parametrical Three-Dimensional Model of a Product.” In: Proceedings of the Twelfth International Conference on Geometry and Graphics. Salvador, Brazil, ISGG, P.\# A19.

[46] Brailov A. Yu (2008). "A Theoretical Approach to Transformations of Two-Dimensional and
Three-Dimensional Models of the Product." In: Proceedings of the Thirteenth International Conference on Geometry and Graphics. Dresden, Germany, ISGG, pp. 58-59.

[47] Brailov A. Yu (2010). "Fundamental Principles of Design and Technological Development of an Engineering Product.” In: Proceedings of the Fourteenth International Conference on Geometry and Graphics. Kyoto, Japan, ISGG, pp. 324-325.

[48] Brailov A. Yu (2011). "Principles of Product Development: Engineering Graphics BALTGRAF11.” In: Proceedings of the Eleventh International Conference. Tallinn, Estonia, IAB: Tallinn University of Technology Publ., pp. 95-104.

[49] Brailov A. Yu (2012). "Laws of Projective Connections.” In: Proceedings of the Fifteenth International Conference on Geometry and Graphics. Montreal, Canada, ISGG, pp. 121-122.

[50] Brailov A. Yu (2011). "Principles of Design and Technological Development of Product.” International Journal of Advances in Machining and Forming Operations 3 (1): 11-17.

[51] Brailov A. Yu (2014). "The General Approach to the Solution of Typical Engineering Geometrical Problems.” In: Proceedings of the Sixteenth International Conference on Geometry and Graphics. Innsbruck, Austria, ISGG, Innsbruck University Press Publ., pp. 444-458.

[52] Bronstein, I. H and Semendjaev, K. A. (1986). Handbook on the Mathematician for Engineers and Pupils of Technical Colleges. Moscow, Science Publ., p. 544 (in Russian).

[53] Korn Г., and Korn T. (1978). Mathematical Handbook for Scientists and Engineers. Moscow, Science Publ., p. 832 (in Russian).

[54] Brailov, A. Yu (2016). Engineering Graphics. Theoretical Foundations of Engineering Geometry for Design. Springer International Publishing, p. 340. 